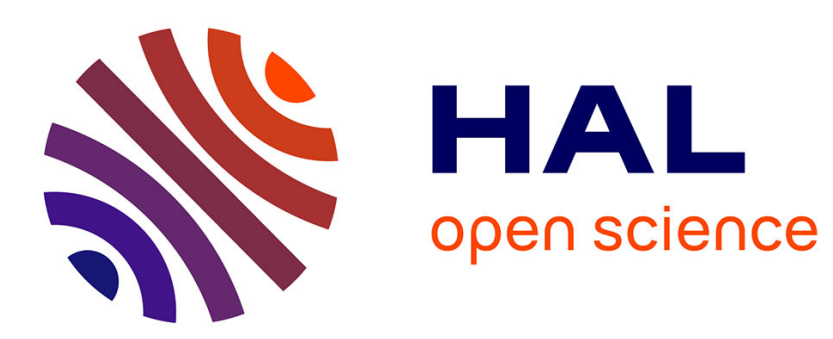

\title{
Empirical and computational studies on newly synthesis cyclohexylammonium perchlorate
}

\author{
C. Daghar, N. Issaoui, Thierry Roisnel, V. Dorcet, H. Marouani
}

\section{To cite this version:}

C. Daghar, N. Issaoui, Thierry Roisnel, V. Dorcet, H. Marouani. Empirical and computational studies on newly synthesis cyclohexylammonium perchlorate. Journal of Molecular Structure, 2021, 1230, pp.129820. 10.1016/j.molstruc.2020.129820 . hal-03130448

\author{
HAL Id: hal-03130448 \\ https://hal.science/hal-03130448
}

Submitted on 19 Feb 2021

HAL is a multi-disciplinary open access archive for the deposit and dissemination of scientific research documents, whether they are published or not. The documents may come from teaching and research institutions in France or abroad, or from public or private research centers.
L'archive ouverte pluridisciplinaire HAL, est destinée au dépôt et à la diffusion de documents scientifiques de niveau recherche, publiés ou non, émanant des établissements d'enseignement et de recherche français ou étrangers, des laboratoires publics ou privés. 
Empirical and computational studies on newly synthesis cyclohexylammonium perchlorate

Chaima Daghar ${ }^{\mathrm{a}}$, Noureddine Issaoui ${ }^{\mathrm{b}}$, Thierry Roisnel ${ }^{\mathrm{c}}$, Vincent Dorcet ${ }^{\mathrm{c}}$, and Houda Marouani ${ }^{\mathrm{a} h o u d a m a r o u a n i 2015 @ g m a i l . c o m ~}$

${ }^{a}$ Université de Carthage, Faculté des Sciences de Bizerte, LR13ES08 Laboratoire de Chimie des Matériaux, 7021, Bizerte,Tunisie

${ }^{b}$ University of Monastir, Laboratory of Quantum and Statistical Physics LR18ES18, Faculty of Sciences, Monastir 5079, Tunisia

'Univ Rennes, CNRS, ISCR (Institut des Sciences Chimiques de Rennes) - UMR 6226, F-35000 *Corresponding email.

Rennes, France

\section{Highlights}

- The novel compound $\left(\mathrm{C}_{6} \mathrm{H}_{14} \mathrm{~N}\right) \mathrm{ClO}_{4}$ has been elaborated by slow evaporation.

- Optimized geometry and UV-Vis spectrum were computed using DFT method

- Vibration modes of the compound were identified by IR analysis.

- The intermolecular interactions were analyzed by HS, AIM and RDG.

- Dipole moment, polarizability and hyperpolarizability values were computed.

Abstract

Cyclohexylammonium perchlorate $\left(\mathrm{C}_{6} \mathrm{H}_{14} \mathrm{~N}\right) \mathrm{ClO}_{4}$ have been achieved from the mixture of perchloric acid with an ethanol solution containing cyclohexylamine by slow evaporation technique. The structure of this compound has been determined by single crystal X-ray diffraction method. This compound crystallizes in monoclinic $\mathrm{P} 2{ }_{1} / \mathrm{c}$ space group with the lattice parameters $\mathrm{a}=11.1501(19) \AA, \mathrm{b}=8.4987(15) \AA, \mathrm{c}=9.9517(16) \AA, \beta=104.166(6){ }^{\circ}$, $\mathrm{Z}=4$ and $\mathrm{V}=914.4(3) \AA^{3}$. The FT-IR was used to identify the different vibrational assignments present in the compound. The optical properties were analyzed by UV-Vis spectral analysis. The intermolecular interactions in the crystal structure were examined via topological Atom-in-Molecules (AIM), Natural Bond Orbital (NBO) and Hirshfeld surface (HS) analyses. Reduced density gradient (RDG) was used to study non-covalent interactions. HOMO-LUMO orbital energies were studied by using DFT calculations at B3LYP/6$311++\mathrm{G}(\mathrm{d}, \mathrm{p})$ level of theory.

\section{Keywords}

Single crystal X-diffraction analysis; IR spectrum; UV-Vis spectroscopy Hirshfeld surface; NMR, NBO

1. Introduction

Hybrid materials have attracted a great of attention because they bring together the properties of organic and inorganic molecules. This combination of these two materials can also lead to completely new properties. 
For several years numerous research works have been devoted to the preparation of hybrid organic-inorganic materials [1]. This new area of research particularly interesting in materials science covering many fields of applications: biology [2-3], optics, electrical conductivity, photochemistry [4-5], medicine [6-7], and photo catalysis [8].

In particular hybrid compounds based on perchlorates have been studied because of interesting physical properties that they present as the ferroelectricity [9] and nonlinear optics [10]. They are characterized by their extreme solubility as well as the high degree of their ionic character.

Perchlorates are salts of perchloric acid, the latter are characterized by the presence of the perchlorate ion $\mathrm{ClO}_{4}{ }^{-}$, consisting of a chlorine atom surrounded by four oxygen atoms as a regular tetrahedron. The perchlorate anions are linked to each other through strong intrapolyanionic bonds. They are mainly found in salts like ammonium perchlorates $\mathrm{NH}_{4} \mathrm{ClO}_{4}$, potassium $\mathrm{KClO}_{4}$, magnesium $\mathrm{MgClO}_{4}$, or sodium $\mathrm{NaClO}_{4}$. This inorganic compound found in the air, in the soil and in water. They have been detected in drinking water in communities around the United States [11] as well as in a variety of food products such as lettuce and wheat [12-13]. They have also been reported in urine [14], breast milk [15] and blood serum in the United States [16].

Perchlorates are widely used as oxidants in energy materials such as propellants and explosives. In addition, perchlorate is a chemical used in the military, aerospace and industries to produce rocket fuel, fires fireworks and for the manufacture of paint.

In this work we report our investigations on a new perchlorate hybrid $\left(\mathrm{C}_{6} \mathrm{H}_{14} \mathrm{~N}\right) \mathrm{ClO}_{4}$ which was identified by single crystal X-ray diffraction. Within this context chemical preparation, structural study, Hirshfeld analysis and infrared spectroscopy are discussed. In addition theoretical calculation was used to simulate and interpret the infrared and UV-visible spectra and revealed with the experimental values.

The electronic properties are determined from HOMO-LUMO orbital analyses. In addition the topological properties AIM and thermodynamical properties are also discussed.

\section{Experimental details}

\subsection{Synthesis and crystallization}

Stoichiometric solution of perchloric acid (0.1 g, $1 \mathrm{mmol}$, purity 96\%, Aldrich) is added dropwise to a solution of cyclohexylamine (0.1 g, $1 \mathrm{mmol}$, purity 99\%, Aldrich) dissolved in ethanol. The mixture is left under stirring at room temperature for 30 minutes. 
Two weeks later single crystals of $\left(\mathrm{C}_{6} \mathrm{H}_{14} \mathrm{~N}\right) \mathrm{ClO}_{4}$ are formed into fine colorless needles. The crystals can be stable for months under normal conditions of temperature and humidity.

Schematically the reaction can be written as follow:

\section{口}

Elemental analysis, calc. (found): C, 36.07\% (36.12); H, 7.01\% (7.08); N, 7.01\% (6.98). Melting point temperature $=513 \mathrm{~K}$.

\subsection{Investigation techniques}

\subsubsection{X-ray data collection}

The intensity data were collected by means of a D8 VENTURE Bruker-AXS diffractometer equipped with Multilayer monochromator and MoK $\alpha$ radiation $(\lambda=0.71073$ $\AA$ ) at $150 \mathrm{~K}$. Absorption corrections were performed using the multi-scan technique using the SADABS program [17]. The total number of measured reflections was 8245 among which 2083 were independent and 1511 had the intensity $\mathrm{I}>2 \sigma(\mathrm{I})$.

The structure was solved by direct methods using SHELXS-97, which revealed the position of all non-hydrogen atoms, and then refined with full-matrix least-square methods based on $\mathrm{F}^{2}$ (SHELXL-97) [18] included in the WINGX program [19].

A final refinement on $\mathrm{F}^{2}$ converged at $\mathrm{R}\left(\mathrm{F}^{2}\right)=0.053$ and $\mathrm{wR}\left(\mathrm{F}^{2}\right)=0.143$. A summary of the crystallographic data and the structure refinements are given in Table 1.

Supporting data (CIF files) have been deposited in the Cambridge Crystallographic Data centre as supplementary materials $\mathrm{N}^{\circ}$ CCDC 1998687. Copies of the data can be obtained, free of charge via www.ccdc.cam.ac.uk/data_request/cif or from the Cambridge Crystallographic Data Centre, 12 Union Road, Cambridge CB21EZ, UK; or by email to deposit@ccdc.cam.ac.uk.

\subsubsection{Physical measurements}

IR spectrum was recorded at room temperature in the frequency range $4000-400 \mathrm{~cm}^{-1}$ with a Perkin-Elmer FT-IR 1000 spectrometer using the technique of pellets with $\mathrm{KBr}$ as a dispersant.

Solid state UV-Vis spectrum was registered with a Perkin-Elmer Lambda 35 spectrophotometer in the range of 200-800 $\mathrm{nm}$.

The ${ }^{13} \mathrm{C}$ NMR experimental spectrum was recorded by employing BRUKER $400 \mathrm{MHz}$ NMR spectrometer in DMSO solvent using tetramethylsilane (TMS) as the reference material.

\subsection{Computational details}


The molecular geometry optimization has been performed with the Gaussian 09 software package [20] and the GaussView molecular visualization program [21] by using the Density functional theory (DFT) with the Becke-three-parameter hybrid exchange functional combined with the Lee-Yang-Parr correlation functional (B3LYP) [22-23] levels, the 6$311++\mathrm{G}(\mathrm{d}, \mathrm{p})$ basis set was used for all. Many theoretical calculations shows that for molecules that exhibits inter or intra-molecular interactions, the B3LYP-D3 functional corrected for dispersion is most preferred [24]. That's why in this paper, we have regard to correction of the Grimme at D3 [25].

All the calculations have converged to an optimized geometry that corresponds to the lowest energy. Positive vibrational frequencies obtained confirming the stability of the optimized geometries.

The vibrational assignments were performed considering the potential energy distribution components $(\mathrm{PED}) \geq 10 \%$ using the VEDA4 package. The GaussView molecular visualization program [26] was used to verify the assignments of the bands.

To examine the contacts in the crystal, Hirshfeld surfaces mapped with $\mathrm{d}_{\text {norm }}$ and their associated 2D fingerprint offered in this paper were plotted using Crystal Explorer version 3.1 software [27] imported on a CIF file. The topological properties at the BCPs were determined with the Multiwfn program [28] while the reduced density gradient of the title molecule are graphed by Multiwfn and plotted by the VMD program [29].

Also, the analysis of the structure was examined using ${ }^{13} \mathrm{C} N M R$ spectroscopic techniques DFT/gauge-including atomic orbitals (GIAO) methods [30].

\section{Results and discussion}

\subsection{X-ray diffraction and geometry optimization}

The title compound crystallizes in the monoclinic system, space group $\mathrm{P} 2{ }_{1} / \mathrm{c}$ and four formula units in unit cell with the lattice constants of $\mathrm{a}=11.1501$ (19) $\AA, \mathrm{b}=8.4987$ (15) $\AA$, $\mathrm{c}=$ 9.9517(16) $\AA$ and $\beta=104.166(6)^{\circ}$. The asymmetric unit of the synthesized compound is formed by a monoprotonated cationic entity which is cyclohexylammonium $\left(\mathrm{C}_{6} \mathrm{H}_{11} \mathrm{NH}_{3}{ }^{+}\right)$and an anionic entity which is the perchlorate ion $\left(\mathrm{ClO}_{4}{ }^{-}\right)$. The optimized geometry of the title compound was performed using Gaussian program [20] and their interface Gauss view [21] is given in Fig.1. The minima energy structure is found with ground state energy calculated to be $-28626.3759 \mathrm{eV}$. The junction between the cations and anions is provided by hydrogen bonds of type $\mathrm{N}-\mathrm{H} \ldots \mathrm{O}$ and $\mathrm{C}-\mathrm{H} \ldots \mathrm{O}$. The organic entity presents a disorder which is manifested by the thermal agitation of all the atoms of hydrogen, nitrogen and carbon. The 
structure is characterized by a succession of cationic and anionic layers along the axis $\vec{a}$ which extends in $x=1 / 2$ (Fig. 2a) which are linked to a further by additional hydrogen bonds, therefore forming the three dimensional infinite network. The projection of such a layer is given in (Fig.2b). The protonation on the $\mathrm{N}$ site of the cation is confirmed from the elongated C-N bond distance $\left(\mathrm{d}_{\mathrm{N}-\mathrm{C}}=1.493 \AA\right.$ ) (Table 2) are similar to those observed in other compounds with the same amine [31-34]. In addition the $\mathrm{C}-\mathrm{C}$ bond lengths experimental are between 1.427 and $1.546 \AA$. We notice that there is not a big difference between the experimental and theoretical bond lengths: in gas the C-C bond lengths vary from 1.527215365, in solution C-C vary from $1.527 \AA-1.536 \AA$ (without dispersion) and $1.526 \AA-1.535 \AA$ (with dispersion). Cyclohexanammonium which is formed by a cyclohexyl group adopts a chair conformation with an ammonium group in equatorial position with bond angles $\mathrm{C}-\mathrm{C}-\mathrm{C}$ vary from $109.441^{\circ}-116.233^{\circ}$ and $\mathrm{N}-\mathrm{C}-\mathrm{C}$ vary from $112.349^{\circ}-114.105^{\circ}$. By comparison between the theoretical and experimental binding angles there is a slight difference. This is due to the fact that the theoretical calculations have been carried out on isolated molecule in gaseous phase whereas the experimental results correspond to molecules in solid state. In addition it is noted that the lengths of the experimental $\mathrm{C}-\mathrm{H}$ bond are shorter than the theoretical bond lengths. The examination of the perchlorate anion shows that the group $\mathrm{ClO}_{4}$ is formed by a regular arrangement of oxygen atoms with a chlorine atom which presents a slight displacement of the center of gravity of the tetrahedron $\delta=0.018 \AA$.

In this context the calculated average values of distortion $\mathrm{Cl}-\mathrm{O}, \mathrm{O}-\mathrm{O}$ distance indices and $\mathrm{O}-$ $\mathrm{Cl}-\mathrm{O}$ angles in the $\mathrm{ClO}_{4}$ tetrahedra according to the Baur method [35] are: $\mathrm{ID}(\mathrm{ClO})=0.0062$; $\mathrm{ID}(\mathrm{OO})=0.0038$ and $\mathrm{ID}(\mathrm{OClO})=0.0057$, show a strong distortion of $\mathrm{Cl}-\mathrm{O}$ distances compared to O-O. However these values are comparable with the corresponding values observed for molecules containing the perchlorate anion [36-38].

The packing for $\left(\mathrm{C}_{6} \mathrm{H}_{14} \mathrm{~N}\right) \mathrm{ClO}_{4}$ are established by hydrogen bonding (Table 3) of types $\mathrm{N}$ H...O and C-H...O. It's worth noting that N-H...O hydrogen bonds are bi and trifurcated with donor-acceptor distances varying between $2.922(14)$ and 3.32 (3) A. Whereas, C-H...O interactions are non-bifurcated with donor-acceptor distances ranging from 3.183 (6) to 3.325 (6) $\AA$.

\subsection{Hirshfeld surface analysis}

The Hirshfeld surface (HS) analysis of the asymmetric unit provides insight into the presence of hydrogen bonds and intermolecular interactions in crystal packing [39]. The threedimensional Hirshfeld surfaces as well as the two-dimensional fingerprints of the asymmetrical unit $\left(\mathrm{C}_{6} \mathrm{H}_{14} \mathrm{~N}\right) \mathrm{ClO}_{4}$ were calculated using the Crystal Explorer program [27] 
based on the results of X-ray studies in CIF format. The Hirshfeld surfaces mapped over $\mathrm{d}_{\text {norm }}$ is illustrated in Fig.3. The surfaces are shown as transparent to allow visualization of the orientation and conformation of the functional groups in the crystal.

The interaction between the hydrogen atoms carried by the nitrogen atoms of the organic group and the oxygen atoms of the inorganic group as well as the hydrogen atoms of the organic groups linking the oxygen atoms of the perchlorate group (Table 3) can be seen on the surface of Hirshfeld as bright red areas in Fig.3. The light red spots are due to the $\mathrm{C}-\mathrm{H}$...O and N-H...O interactions (see Table 3). These red spots have the shortest intermolecular contacts. The white spots correspond to the type $\mathrm{H} \ldots \mathrm{H}$ interaction and the blue spots illustrate the longest contacts in the structure.

More the Fig.4 illustrates the two-dimensional fingerprint of the totality contacts contributing to the surface Hirshfeld represented in $d_{\text {norm }}$ mode where the $\mathrm{O}$..H/H... interactions have the largest contributions on the Hirshfeld surface 53.4\% and appears by two symmetrical wings with $d_{e}+d_{i} \sim 2 \AA$. These data are characteristic of hydrogen bonds N-H...O and CH...O. The H ... H contacts comprise $44.2 \%$ of the total area Hirshfeld surface. They are characterized by two extremities which point to the origin and which correspond to $\mathrm{d}_{\mathrm{e}}+\mathrm{d}_{\mathrm{i}} \sim 2 \AA$. The $\mathrm{O}$... O contacts are also visible on the HS and this contact of around $2.8 \AA$. This graphic is characterized by two wings and which correspond to $d_{e}+d_{i} \sim 3.2 \AA$. We find that the contacts $\mathrm{O} \ldots \mathrm{H} / \mathrm{H} \ldots \mathrm{O}$ and $\mathrm{H} \ldots \mathrm{H}$ are considered to be close contacts with a sum of $\mathrm{d}_{\mathrm{e}}+\mathrm{d}_{\mathrm{i}}$ less than or equal to the sum of the van der Waals radii of the atoms involved $(\mathrm{H}: 1.09$ $\AA$, O: $1.52 \AA$ ). The intermolecular interactions were additional evaluated by using the enrichment ratio, $E R$. The enrichment ratio $\mathrm{ER}_{\mathrm{XY}}$ of a pair of chemical elements $(\mathrm{X}, \mathrm{Y})$ is defined as the ratio between the proportion of actual contacts in the crystal and the theoretical proportion of random contacts [40].

Table 4 shows the enrichment ratios of the main intermolecular interactions for the compound. The O... H/H...O contacts appear with an enrichment ratios larger than unity $\left(\mathrm{RE}_{\mathrm{OH}}=1.29\right)$ which prove to be favored in the crystal package with the formation of the NH... O and C-H... O type hydrogen bonds. On the other hand, the $\mathrm{H} \cdots \mathrm{H}$ contacts appear with an enrichment ratios close to unity $\left(\mathrm{RE}_{\mathrm{OH}}=0.88\right)$. It's worth noting that $\mathrm{O} \ldots \mathrm{H} / \mathrm{H} \ldots \mathrm{O}$ and $\mathrm{H}$...H contacts are most plentiful interactions because hydrogen atoms occupy more than half of the molecular surface $\left(\% \mathrm{~S}_{\mathrm{H}}=70.9 \%\right)$.

\subsection{Quantum theory of atoms in molecules (QTAIMs) analysis}

Atoms-In-Molecule (AIM) analysis is an efficient tool to determine the presence of critical points (CPs). This point is used for the identification of chemical bonds between atoms and 
interatomic interaction. The topological parameters proposed by Bader [41] can be calculated in the bond critical point using the Multiwfn program [28] such as the electron density $\rho(r)$, the Laplacian values $\nabla^{2} \rho(r)$, the ellipticity $(\varepsilon)$, which makes it possible to evaluate the properties of the bonds in the compound and more particularly the hydrogen bonds. The latter can be classified into three categories according to Rozas et al. [42]:

- Weak hydrogen bonds: $\nabla^{2} \rho\left(\mathrm{r}_{\mathrm{BCP}}\right)>0$ and $\mathrm{H}\left(\mathrm{r}_{\mathrm{BCP}}\right)>0$

- Moderate hydrogen bonds: $\nabla^{2} \rho\left(\mathrm{r}_{\mathrm{BCP}}\right)>0$ and $\mathrm{H}\left(\mathrm{r}_{\mathrm{BCP}}\right)<0$

- Strong or very strong hydrogen bonds: $\nabla^{2} \rho\left(\mathrm{r}_{\mathrm{BCP}}\right)<0$ and $\mathrm{H}\left(\mathrm{r}_{\mathrm{BCP}}\right)<0$

The graphical representation of AIM analysis of the $\left(\mathrm{C}_{6} \mathrm{H}_{14} \mathrm{~N}\right) \mathrm{ClO}_{4}$ compound is illustrated in Fig.5 and the calculated topological parameters are assembled in Table 5.

The AIM topological analysis reveals that our crystal is stabilized by three hydrogen bonds H...O. The BCP analysis in Table 5 shows that the three O..H bonds are considered weak with hydrogen bond energies of $-4.34 ;-28.57$ and $-1.81 \mathrm{kcal} / \mathrm{mol}$. The laplacian of electron density $(0.01725,0.09187,0.00984)$ and the energy density $(0.00602,0.02967,0.00264)$ confirm the strength of these hydrogen bonds. These values are greater than zero according to the Rozas criterion. In addition, the AIM analysis allows us to detect the presence of cycles in a molecular system through the presence of a new ring critical point "RCP" and NRCP1 and NRCP2 cycles that are formed through the interactions between the organic group and the perchlorate anion via hydrogen bonds as shown in Fig.5.

To conclude we can say that the AIM analysis is used to confirm the $\mathrm{H}$... H contacts that are already observed by Hirshfeld surface analysis and to detect the presence of cycles in a molecular system.

\subsection{Reduced density gradient analysis}

The weak interactions play an important role in many of physical, chemical or biological phenomena [43]. They can be used in various applications such as hydrogen storage for renewable energies [44]. Reduced density gradient (RDG) is a very popular and powerful method for analyzing weak interactions such as repulsive interactions, van der Waals interactions and hydrogen bonds using a simple color code. The RDG approach is based on the charge density introduced by Johnson et al. [45] and Contreras-Garcia et al. [46].

Figs. $6 a$ and $6 \mathrm{~b}$ gives a visualization of non covalent interaction in the molecular space of $\left(\mathrm{C}_{6} \mathrm{H}_{14} \mathrm{~N}\right) \mathrm{ClO}_{4}$ molecule by using VMD and Multiwfn programs [29,28], respectively. Fig. $6 \mathrm{~b}$ illustrates the RDG function versus the electron density $\rho$ multiplied by the sign of the second 
eigenvalue $\lambda_{2}$ for $\left(\mathrm{C}_{6} \mathrm{H}_{14} \mathrm{~N}\right) \mathrm{ClO}_{4}$ compound. Through a color code we can differentiate between different regions of interactions (show Fig. 6c). This figure highlights regions of color that allows us to describe the type of interaction. When sign $(\lambda 2) \rho$ take a negative value, we have a strong attractive interactions (blue color). Strong repulsive interactions when sign ( $\lambda 2) \rho$ have a positive value (red color). The last case, we have van der Waals interactions when sign ( $\lambda 2) \rho$ is close to zero (green color).

As clearly seen, the blue spot between the oxygen atom carried by the nitrogen atom and the oxygen atom carried by the perchlorate group indicates the formation of a strong attractive interaction $\mathrm{N}-\mathrm{H}$... O. Moreover the green plates with slight brown located between the hydrogen atoms are attributed to van der Waals interactions and the elliptic red plate located at the center of the cycle is related to repulsive interactions. These results are consistent with that of the AIM analysis.

\subsection{Thermodynamic Analysis}

The thermodynamic parameters of the title compound are shown in Table 6. These thermodynamic parameters were calculated by DFT methods with 6-311++G $(\mathrm{d}, \mathrm{p})$ basis set at a constant temperature $298.15 \mathrm{~K}$ and pressure $\mathrm{P}=1 \mathrm{~atm}$.

As can be seen from the table, the value of the dipole moment in solution is greater compared to that of the gas phase. This high value is explained by the high delocalization of a pair of electrons isolated in the perchlorate group where the perchlorate anion has four oxygen atoms. Moreover, the values of the polarizability $\alpha$ in the solution with and without dispersion are almost equivalent ( $\alpha=155.83876$ a.u and $\alpha=155.5042$ a.u respectively) and greater than those obtained in the gas phase $(\alpha=112.22611$ a.u.). A great difference is noted for the hyperpolarizability $\beta$ values in the solution with and without dispersion $(\beta=196.82125$ a.u. and $\beta=146.93182$ a.u., respectively) and in the gas phase $(\beta=391.90919$ a.u. $)$.

\subsection{Frontier molecular orbital analysis}

The frontier molecular orbitals are two types: highest occupied molecular orbital (HOMO) and lowest unoccupied molecular orbital (LUMO). The difference between these two orbitals called gap energy is useful to characterize the chemical stability of a molecule. A high gap indicates a high stability of the molecule and therefore low reactivity and vice versa. The HOMO, HOMO-1, LUMO, LUMO+1 orbitals as well as the gap energy calculated in the gas phase are mapped in Fig.7 in which red and green regions represent positive and negative phase, respectively. 
The energy values of HOMO, LUMO, LUMO+1, HOMO-1 were calculated from the TDDFT method associate B3LYP/6-311++G $(\mathrm{d}, \mathrm{p})$ are: $\mathrm{E}_{\mathrm{HOMO}}=-7.640 \mathrm{eV} ; \mathrm{E}_{\mathrm{LUMO}}=-1.210 \mathrm{eV}$; $\mathrm{E}_{\mathrm{LUMO}+1}=-0.610 \mathrm{eV} ; \mathrm{E}_{\mathrm{HOMO}-1}=-7.673 \mathrm{eV}$, corresponding to HOMO-LUMO gap of $6.429 \mathrm{eV}$ and HOMO-1-LUMO+1 gap of $7.063 \mathrm{eV}$. Moreover the $\mathrm{E}_{\mathrm{HOMO}}$ and $\mathrm{E}_{\mathrm{LUMO}}$ values are easily used to calculate the chemical hardness $\left(\eta=\frac{(I-A)}{2}\right)$, the global softness $\left(\mathrm{S}=\frac{1}{2 \eta}\right)$, the electron affinity $\left(\mathrm{I}=-\mathrm{E}_{\mathrm{HOMO}}\right)$ and the ionization potential $\left(\mathrm{A}=-\mathrm{E}_{\mathrm{LUMO}}\right)$. Also, the values of electronegativity can be determined according to the definition of Mulliken [47] $\left(\chi=\frac{(I+A)}{2}\right)$, the global chemical potential $\left(\mu=-\frac{(I+A)}{2}\right)$ and the global electrophilicity introduced by Parr et al. [48] $\left(\omega=\frac{\mu^{2}}{\eta}\right)$. Table 7 regroups all the calculated values of chemical reactivity descriptors. From the above values, we can see that the value of the gap energy is high then means a high kinetic stability and a low chemical reactivity. Comparing the gap energy in gas phase and in solution, we observed that $\left(\Delta \mathrm{E}_{\mathrm{Gas}}<\Delta \mathrm{E}_{\text {solution }}\right)$. In addition, the values of the chemical potential $(\mu)$ are negative which implies that our molecule is quite stable. From the previously results we can deduce that our compound in solution is more stable than in the gas phase. Also the smaller value of global hardness $\eta$ means that the compound has a high polarizability. Finally we notice that the electrophilicity index has decreased $\omega_{\text {gas }}<\omega_{\text {solution }}$ this is used to evaluate the lowering of energy due to maximal electron flow between donors and acceptors.

\subsection{Electronic properties}

The experimental electronic absorption spectrum of title compound has been measured in DMSO solvents at room temperature while the theoretical spectrum was determined by using B3LYP/6-311++G(d,p) level of theory in the same solvent. Experimental and theoretical spectra are shown in Figs.8a and 8b. The two spectra exhibit two peaks of different intensity and wavelengths. Experimentally, the broad and intense band observed at $340 \mathrm{~nm}$ can be attributed to the $n-\pi^{*}$ transition of the anion perchlorate while the less intense peak located at $260 \mathrm{~nm}$ is assigned to a charge transfer transition. Theoretically, the spectrum has two intense bands also at $380 \mathrm{~nm}$ which corresponds to $\mathrm{n}-\pi^{*}$ and at $270 \mathrm{~nm}$ which corresponds to a charge transfer transition. The optical band gap energy is determined by the Tauc method [49] by plotting $(\alpha h v)^{2}$ versus hu as shown in Fig. 8c. Gap energy (Eg) can be calculated by extrapolating the linear part and is found to be $6.23 \mathrm{eV}$. This value reveals that the crystal is a typical of dielectric material [50]. This result confirms that the experimental result is in good agreement with the theoretical calculation $(\mathrm{Eg}=6.429 \mathrm{eV})$. 


\subsection{Vibrational analysis}

FT-IR spectroscopy is a widely used technique for measuring and identifying the vibrational frequencies of atomic groups of compounds. The FTIR spectrum of $\mathrm{C}_{6} \mathrm{H}_{14} \mathrm{~N}\left(\mathrm{ClO}_{4}\right)$ was measured between 4000 and $400 \mathrm{~cm}^{-1}$ and compared to the theoretical spectrum by using the density functional theory (DFT) method associated with the B3LYP/6-311++G (d,p) basis set on the optimized geometries of the compound with $\mathrm{ClO}_{4}$ group in monodentate coordination mode. The calculated and experimental infrared spectra are shown in Fig.9a and b respectively. This figure shows a good correlation between the theoretical and experimental spectra with a small difference which may be due to the fact that the experimental spectrum is measured in the crystalline phase although the theoretical spectrum is measured in the gas phase. The experimental and the calculated infrared wavenumber are provided in Table 8 . Based on the bibliographic study [33, 36, 51-54], the different modes of vibration of the perchlorate anion as well as the organic cation have been assigned to all the bands appeared in the IR spectrum.

\subsection{1. $\mathrm{ClO}_{4}$ - vibrations analysis}

In the Free State, the $\mathrm{ClO}_{4}$ group adopts a regular tetrahedral structure with tetrahedral symmetry $\left(\mathrm{T}_{\mathrm{d}}\right)$, having nine degrees of freedom of vibration distributed between four normal vibration modes: $\Gamma=\mathrm{A}_{1}+\mathrm{E}+2 \mathrm{~F}_{2}$.

These normal modes of vibration are: symmetric stretching $v_{1}\left(A_{1}\right)$, symmetric deformation $v_{2}$ (E), asymmetrical stretching $v_{3}\left(\mathrm{~F}_{2}\right)$ and asymmetrical deformation $v_{4}\left(\mathrm{~F}_{2}\right)$. All the modes are Raman active, whereas only $v_{3}$ and $v_{4}$ are active in the IR [55] and are expected to occur at $928,459,1119$ and $625 \mathrm{~cm}^{-1}$, respectively [56,57]. Here, The $v_{3}\left(F_{2}\right)$ stretching vibration appears as one intense band at $1079 \mathrm{~cm}^{-1}$, whereas the calculated frequency of this vibration is $929 \mathrm{~cm}^{-1}$. The band observed at $624 \mathrm{~cm}^{-1}$ is assigned to $v_{4}\left(F_{2}\right)$ asymmetric bending. The theoretical frequency of $v_{4}\left(\mathrm{~F}_{2}\right)$ mode was found at $538 \mathrm{~cm}^{-1}$. The band due to symmetric stretching $v_{1}\left(A_{1}\right)$ is obtained at $923 \mathrm{~cm}^{-1}$ and calculated at $890 \mathrm{~cm}^{-1}$. The symmetric bending is observed at $453 \mathrm{~cm}^{-1}$. The DFT calculations give this mode at $394 \mathrm{~cm}^{-1}$.

\subsection{2. $\mathrm{C}_{6} \mathrm{H}_{11} \mathrm{NH}_{3}{ }^{+}$vibrations}

The N-H stretching vibration is located in the region $3457-3132 \mathrm{~cm}^{-1}$ and $3345-3142$ $\mathrm{cm}^{-1}$ in B3LYP methods, respectively, shows good accord with literature studies [58] as well as recorded spectrum.

The band observed at $1590 \mathrm{~cm}^{-1}$ is assigned to the asymmetric bending mode of $\mathrm{N}-\mathrm{H}$ and which corresponds to a theoretical value $1592 \mathrm{~cm}^{-1}$. The symmetric bending modes of $\mathrm{N}-$ 
$\mathrm{H}$ assigned to the band of medium intensity at $1581 \mathrm{~cm}^{-1}$ and which corresponds to a theoretically predicted value at $1580 \mathrm{~cm}^{-1}$.

The asymmetric and symmetric stretching vibrations of $\mathrm{CH}_{2}$ are observed at 2952 and 2859 $\mathrm{cm}^{-1}$ respectively. Whereas, these vibrations are calculated at $v_{\mathrm{as}}=2960 \mathrm{~cm}^{-1}$ and $v_{\mathrm{s}}=2882 \mathrm{~cm}^{-1}$. The band observed at $1447 \mathrm{~cm}^{-1}$ is assigned to the symmetric bending mode $\delta_{\mathrm{s}}$ and is predicted at $1448 \mathrm{~cm}^{-1}$ in DFT method.

The bands at $923 \mathrm{~cm}^{-1}$ are attributed to the $\mathrm{C}-\mathrm{C}$ stretching modes and calculated at $884 \mathrm{~cm}^{-1}$. Also the band observed at $1079 \mathrm{~cm}^{-1}$ is attributed to the stretching vibration of the group C-N and predicted by DFT calculation at $939 \mathrm{~cm}^{-1}$. Besides, the band situated at $453 \mathrm{~cm}^{-1}$ corresponds to the $\mathrm{C}-\mathrm{C}-\mathrm{C}$ bending vibrations. This mode it is theoretically calculated at 450 $\mathrm{cm}^{-1}$ by DFT method.

According to this attribution, a good analogy is observed between the theoretical and experimental spectra with a small difference which may be due to the fact that the experimental spectrum is measured in the crystalline phase although the theoretical spectrum is measured in the gas phase.

\subsection{Nuclear magnetic resonance studies}

The ${ }^{13} \mathrm{C}$ NMR spectral analysis is the most important analytical technique used to confirm the chemical structure of $\left(\mathrm{C}_{6} \mathrm{H}_{14} \mathrm{~N}\right) \mathrm{ClO}_{4}$ crystal. The ${ }^{13} \mathrm{C}$ NMR experimental spectrum is shown in Fig.10 which is quite similar to other spectra found in compounds involving the same organic group [59].

The chemical shift calculations of the compound was made by GIAO [30] method using 6$311+\mathrm{G}(2 \mathrm{~d}, \mathrm{p})$ basis set and reported in ppm relative to TMS. The theoretical ${ }^{13} \mathrm{C}$ NMR chemical shifts of ${ }^{13} \mathrm{C}$ have been compared with the experimental data as shown in Table 9.

Fig. 10 and Table 9 show that theoretically there are six carbon rays, while experimentally there are only four rays. This can be explained by the presence of carbon atoms having the same chemical shifts which are the pairs (C2, C6) and (C3, C5). The DMSO solvent shifts are observed between 39 to $41 \mathrm{ppm}$ in Fig.10. The signal at the chemical shift value of $24.15 \mathrm{ppm}$ is attributed to the two carbons ( $\mathrm{C} 3$ and $\mathrm{C} 5)$ in the form of $-\mathrm{CH}_{2}$ groups of the $\left(\mathrm{C}_{6} \mathrm{H}_{14} \mathrm{~N}\right) \mathrm{ClO}_{4}$ while the calculated shifts were identified from 29.9266 to $29.9303 \mathrm{ppm}$. The NMR signals at 24.99 ppm correspond to the $\mathrm{C} 4$ whereas the computed chemical shift value is $29.2161 \mathrm{ppm}$. The single signal at $30.83 \mathrm{ppm}$ was due to 2 carbon atoms (C2 and C6) with same chemical environment are in good agreement with the measured values (35.8008 and $35.7989 \mathrm{ppm})$. 
The carbon $\mathrm{C} 1$ takes experimentally the value $49.79 \mathrm{ppm}$ and the value $62.9622 \mathrm{ppm}$ theoretically.

\subsection{NBO analysis}

NBO method provides valuable information of conjugative interaction, hyper-conjugative interaction, intra and inter-molecular hydrogen bonding in a compound [60]. The secondorder Fock matrix was carried out to evaluate the donor-acceptor interactions in the NBO analysis [61]. For each donor NBO (i) and acceptor NBO (j), the donor acceptor stabilization energy $\mathrm{E}^{(2)}$ associated with $\mathrm{i} \rightarrow \mathrm{j}$ delocalization is estimated as:

$$
E^{(2)}=q_{i} \frac{F^{2}(i, j)}{\varepsilon_{i}-\varepsilon_{j}}
$$

Where $\mathrm{q}_{\mathrm{i}}$ is the donor orbital occupancy, $\varepsilon_{\mathrm{i}}$ and $\varepsilon_{\mathrm{j}}$ are diagonal elements and $F(\mathrm{i}, \mathrm{j})$ is the off diagonal NBO Fock matrix element. The results of NBO analysis using B3LYP method have been reported in Table 10. The value associated with $\mathrm{E}^{(2)}$ reflects the extent of conjugation present in the system. The delocalization of electron density between occupied and unoccupied orbitals results in the stabilization of donor-acceptor interactions.

The intermolecular interaction is formed by oxygen lone electron pairs $\mathrm{LP}(\mathrm{O} 24)$ and $\sigma *(\mathrm{~N} 1-$ H4) anti-bonding orbitals which is characterized by a stabilizing energy that equals to 6.96 kcal.mol ${ }^{-1}$. This result confirm the existence of hydrogen bonds $\mathrm{N}-\mathrm{H}$...O which are already observed by other analysis such as X-ray diffraction, Hirshfeld surface, AIM and RDG at the level of the compound structure.

\section{Conclusion}

In summary, the $\left(\mathrm{C}_{6} \mathrm{H}_{14} \mathrm{~N}\right) \mathrm{ClO}_{4}$ compound was synthesized and characterized by both experimental and computational methods such as single crystal X-ray diffraction, Elemental analysis, Hirshfeld surface analysis, DFT, ${ }^{13} \mathrm{C}$ NMR, FT-IR and UV-visible spectroscopies. $\mathrm{X}$-ray analysis revealed that the structure crystallizes in the Monoclinic with space group $\mathrm{P} 2{ }_{1} / \mathrm{c}$. The studied compound presents a disorder in the organic entity which is manifested by the thermal agitation of all the hydrogen, nitrogen and carbon atoms. The crystal packing is stabilized by hydrogen bonding network and also by van der Waals interactions.

AIM approach suggests a good stability of title compound. The analysis of the Hirshfeld surface derived fingerprint plots is used to identify and examine the different types of intermolecular contacts. 
Theoretical calculation was used to simulate and interpret the infrared and UV-visible spectra. The electronic properties are determined from HOMO, LUMO and gap energy (Eg) orbital analyzes. In addition, the ${ }^{13} \mathrm{C}$ NMR spectrum confirms the results revealed by X-ray diffraction.

Acknowledgements

We are grateful to the Tunisian Ministry of Higher Education Scientific Research for the provided financial support.

References

[1] J. Wen, G. L. Wilkes, Chem. Mater. 8 (1996) 1667-1681.

[2] L.M. Novena, S.S. Kumar, S. Athimoolam, Improved solubility and bioactivity oftheophylline (a bronchodilator drug) through its new nitrate salt analysed by experimental and theoretical approaches, J. Mol. Struct. 1116 (2016) 45-55.

[3] A. Müller, F. Peters, M.T. Pope, D. Gatteschi, Polyoxometalates: very large clusters-nanoscale magnets, Chem. Rev. 98 (1998) 239-272.

[4] P. Englebienne, A.V. Hoonacker, Goldeconductive polymer nanoparticles: a hybrid material with enhanced photonic reactivity to environmental stimuli, J. Colloid Interface Sci. 292 (2) (2005) 445-454.

[5] A. Müller, H. Reuter, S. Dillinger, Supramolecular inorganic chemistry: small guests in small and large hosts, Angew. Chem. Int. Ed. Engl. 34 (1995) 2328-2361.

[6] P.V. Braun, P. Osenar, V. Tohver, S.B. Kennedy, S.I. Stupp, Nanostructure templating in inorganic solids with organic lyotropic liquid crystals, J. Am.Chem. Soc. 121 (1999) 7302-7309.

[7] M.-C. Daniel, D. Astruc, Gold nanoparticles: assembly, supramolecular chemistry, quantum-size-related properties, and applications toward biology, catalysis, and nanotechnology, Chem. Rev. 104 (2004) 293-346.

[8] Y. Li, Y. Yu, L. Wu, J. Zhi, Processable polyaniline/titania nanocomposites with good photocatalytic and conductivity properties prepared via peroxotitanium complex catalyzed emulsion polymerization approach, Appl. Surf. Sci. 273 (2013) 135-143.

[9] M. Drozd, D.Dudzic, Spectrochim.Acta Part A. (2013) 345-356.

[10] M. K. Marchewka, M Drozd, L-leucinium perchlorate: new molecular complex with nonlinear optical properties. Vibrational, calorimetric and theoretical studies, Cent. Eur. J. Chem. 11(8) (2013) 1264-1277. 
[11] E. N. Pearce, A. M. Leung, B. C. Blount, H. R. Bazrafshan, X. He, S. Pino, L. Valentin-Blasini, L. E. Braverman, JCEM 92 (2007) 1673-1677.

[12] L. Yu, J. E. Cañas, G. P. Cobb, W. A. Jackson, T. A. Anderson, Ecotoxicol. Environ. Saf. 58 (2004) 44-49.

[13] W. A. Jackson, P. Joseph, P. Laxman, K.Tan, P.N.Smith, L.Yu, T.A. Anderson, J. Agric. FoodChem. 53 (2005) 369-373.

[14] B.C. Blount, J.L. Pirkle, J.D.Osterloh, L.Valentin-Blasini, K.L. Caldwell, Environ. Health Perspect. 114 (2006)1865-1871.

[15] A. B. Kirk, P. K. Martinelango, K. Tian, A. Dutta, E. E. Smith, P. K. Dasgupta, Environ. Sci. Technol. 39(2005) 2011-2017.

[16] J. F. Oldi, K. Kannan, Chemosphere 77(2009) 43-47.

[17] Bruker, APEX2, SAINT and SADABS, Bruker AXS Inc., Madison, Wisconsin, USA, 2006.

[18] G.M. Sheldrick, Crystal structure refinement with SHELXL, Acta Crystallogr. C71 (2015) 3-8.

[19] L.J. Farrugia, WinGX and ORTEP for windows: an update, J. Appl. Crystallogr. 45 (2012) 849-854.

[20] M.J. Frisch, G.W. Trucks, H.B. Schlegel, G.E. Scuseria, M.A. Robb, J.R. Cheeseman, G. Scalmani, V. Barone, B. Mennucci, G.A. Petersson, H. Nakatsuji, M. Caricato, X. Li, H.P. Hratchian, A.F. Izmaylov, J. Bloino, G. Zheng, J.L. Sonnenberg, M. Hada, M. Ehara, K. Toyota, R. Fukuda, J. Hasegawa, M. Ishida, T. Nakajima, Y. Honda, O. Kitao, H. Nakai, T. Vreven, J.A. Montgomery Jr., J.E. Peralta, F. Ogliaro, M. Bearpark, J.J. Heyd, E. Brothers, K.N. Kudin, V.N. Staroverov, R. Kobayashi, J. Normand, K. Raghavachari, A. Rendell, J.C. Burant, S.S. Iyengar, J. Tomasi, M. Cossi, N. Rega, J.M. Millam, M. Klene, J.E. Knox, J.B. Cross, V. Bakken, C. Adamo, J. Jaramillo, R. Gomperts, R.E. Stratmann, O. Yazyev, A.J. Austin, R. Cammi, C. Pomelli, J.W. Ochterski, R.L. Martin, K. Morokuma, V.G. Zakrzewski, G.A. Voth, P. Salvador, J.J. Dannenberg, S. Dapprich, A.D. Daniels, O. Farkas, J.B. Foresman, J.V. Ortiz, J. Cioslowski, D.J. Fox, Gaussian, Inc., Wallingford CT, 2009.

[21] R. Dennington, T. Keith, J. Millam, GaussView, Version 5, Semichem. Inc, Shawnee Mission, KS, 2009.

[22] A.D. Becke, Becke's three parameter hybrid method using the LYP correlation functional, J. Chem. Phys. 98 (1993) 5648-5652. 
[23] C. Lee, W. Yang, R.G. Parr, Development of the Colle-Salvetti correlation-energy formula into a functional of the electron density, Phys. Rev. B 37 (1988) 785-789.

[24] O. Noureddine, S. Gatfaoui, S. A. Brandán, H. Marouani, N. Issaoui, Structural, docking and spectroscopic studies of a new piperazine derivative, 1Phenylpiperazine-1,4-diium bis(hydrogen sulfate), J. Mol. Struct. 1202 (2020) 127351.

[25] S. Grimme, J. Antony, S. Ehrlich, H. Krieg, A consistent and accurate ab initio parametrization of density functional dispersion correction (DFT-D) for the 94 elements H-Pu, J. Chem. Phys. 132 (2010), 154104.

[26] M.H. Jamroz, Vibrational Energy Distribution Analysis, vol. 4, VEDA, Poland, 2004. Computer Program.

[27] S.K. Wolff, D.J. Grimwood, J.J. McKinnon, D. Jayatilaka, M.A. Spackamn, CrystalExplorer 3.1, University of WestrenAustralia, Perth, 2013.

[28] T. Lu, F. Chen, Multiwfn: a multifunctional wavefunction analyzer, J. Comput. Chem. 33 (2012) 580-592.

[29] W. Humphrey, A. Dalke, K. Schulten, VMD: visual molecular dynamics, J. Mol. Graph. 14 (1996) 33-38, 27-8.

[30] K. Wolinski, J. F. Hinton, P. Pulay, Efficient implementation of the gauge independent atomic orbital method for NMR chemical shift calculations, J. Am. Chem. Soc. 112 (1990) 8251-8260.

[31] J. Li, Acta Cryst. E67 (2011) o842.

[32] A. A. Bagabas, M. F. A. Aboud, A. M. Shemsi, E. S. Addurihem, Z. A. Al-Othman, C. S. Chidan Kumar, H.-K. Fun, Acta Cryst. E70 (2014) o253.

[33] R. Gomathi, S. Madeswaran, Structural, Thermal and Nonlinear Optical Studies on Novel Organic Cyclohexylammonium Hydrogen Adipate crystal, Mater. Chem. Phy. 218 (2018) 189.

[34] C. Boukoum, S. Besbes-Hentati, N. Derbel, K. Schenk, Z. Aloui, S. Abid, Structural Investigation, Hirshfeld Surface Analysis, characterization and computational studies of a novel chlorobismuthate(III) complex, Chem. Data Collect. 24 (2019) 100289.

[35] W.H. Baur, Acta Crystallogr. B30 (1974) 1191-1195.

[36] A. Guesmi, T. Roisnel, H. Marouani, Featuring non-covalent interactions in mxylylenediaminium bis(perchlorate) monohydrate: Synthesis, characterization and Hirshfeld surface analysis, J. Mol. Struct.1194 (2019) 66-72. 
[37] C. Ben Mleh, T. Roisnel, H. Marouani, Synthesis and crystal structure of a new 2,6dimethylpiperazine-1,4-diium perchlorate monohydrate: $\left[\mathrm{C}_{6} \mathrm{H}_{16} \mathrm{~N}_{2}\right]\left(\mathrm{ClO}_{4}\right)_{2} \cdot \mathrm{H}_{2} \mathrm{O}$, Crystallography Reports 62(2) (2017) 246-248.

[38] C. Ben Mleh, T. Roisnel, H. Marouani, trans-2,5-Dimethylpiperazine-1,4-diium bis(perchlorate) dihydrate: crystal structure and Hirshfeld surface analysis, Acta Cryst. E72 (2016) 593-596.

[39] M. A.Spackman, D. Jayatilaka, Cryst.Eng.Comm.11 (2009) 19-32.

[40] C. Jelsch, K. Ejsmont, L. Huder, The enrichment ratio of atomic contacts in crystals, an indicator derived from the Hirshfeld surface analysis, IUCrJ 1 (2014) 119-128.

[41] R.F.W. Bader, Atoms in Molecules. A Quantum Theory, Oxford University Press, Oxford, 1990, ISBN 0198558651.

[42] I. Rozas, I. Alkorta, J. Elguero. J. Am. Chem. Soc. 122 (2000) 11154-11161.

[43] K. Autumn et al., Proc. Natl. Acad. Sci. U.S.A. 99, 12252_2002; R. L. Baldwin, J. Mol. Biol. 371, 283 2007; P. Hobza et al., J. Am. Chem. Soc. 117, 7921995.

[44] A. C. Dillon et al., Nature London 386, 3771997.

[45] E.R. Johnson, S. Keinan, P. Mori-Sánchez, J. Contreras-García, A.J. Cohen, W. Yang, J. Am. Chem. Soc. 132 (2010) 6498-6506.

[46] J. Contreras-Garcia, W. Yang, E.R. Johnson, Analysis of hydrogen-bond interaction potentials from the electron density: integration of noncovalent interaction regions, J. Phys. Chem. A 115 (2011) 12983-12990.

[47] R.S. Mulliken, A new electroaffinity scale; together with data on valence states and on valence ionization potentials and electron affinities, J. Chem. Phys. 2 (1934) 782-794.

[48] R.G. Parr, L. von Szentpály, S. Liu, Electrophilicity index, J. Am. Chem. Soc. 121 (1999) 1922-1924.

[49] J. Tauc, Optical properties and electronic structure of amorphous $\mathrm{Ge}$ and $\mathrm{Si}$, Mater. Res. Bull. 3 (1968) 37-46.

[50] C. Muthuselvi, N. Rathika, K.Selvalakshmi, Vibrational, Optical and Antimicrobial Activity Studies on Diglycine Perchlorate Single Crystal, App.Sci.19 (2019) 848-856.

[51] S.A. Brandán, Theoretical study of the structure and vibrational spectra of chromyl perchlorate, $\mathrm{CrO}_{2}\left(\mathrm{ClO}_{4}\right)_{2}$, J. Mol. Struct.: THEOCHEM 908 (2009) 19-25.

[52] S. Gatfaoui, N. Issaoui, Silvia A. Brandán, T. Roisnel, H. Marouani, Synthesis and characterization of p-xylylenediaminium bis(nitrate). Effects of the coordination 
modes of nitrate groups on their structural and vibrational properties, J. Mol. Struct. 1151 (2018) 152-168.

[53] C.B. M'leh, S.A. Brandán, N. Issaoui, T. Roisnel, H. Marouani, Synthesis, molecular structure, vibrational and theoretical studies of a new noncentrosymmetric organic sulphate with promising NLO properties, J. Mol. Struct. 1171 (2018) 771-785.

[54] S. Trabelsi, N. Issaoui, S.A. Brandán, F. Bardak, T. Roisnel, A. Atac, H. Marouani, Synthesis and physic-chemical properties of a novel chromate compound with potential biological applications, bis(2-phenylethylammonium) chromate(VI), J. Mol. Struct. 1185 (2019) 168-182.

[55] S. Ramaswamy, R. K. Rajaram, V. Ramakrishnan, J. Raman Spectrosc., 33 (2002) 689-698.

[56] V. Krishnakumar, S. Kalyanaraman, M. Piasecki, I. V. Kityk, P. Bragiel, J. Raman Spectrosc. 39 (2008) 1450-1454.

[57] S. Pandiarajan, R. K. Rajaram, V. Ramakrishnan, J. Raman Spectrosc. 36 (2005) 785-790.

[58] I. Jomaa, O. Noureddine, S. Gatfaoui, N. Issaoui, T. Roisnel, H. Marouani, Experimental, computational, and in silico analysis of $\left(\mathrm{C}_{8} \mathrm{H}_{14} \mathrm{~N}_{2}\right)_{2}\left[\mathrm{CdCl}_{6}\right]$ compound, J. Mol. Struct. 1213 (2020) 128186.

[59] P. Sathya, M. Anantharaja, N. Elavarasu, R. Gopalakrishnan, Growth and characterization of nonlinear optical single crystals: bis(cyclohexylammonium) terephthalate and cyclohexylammonium para-methoxy benzoate, Bull. Mater. Sci. 38

(2015) 1291-1299.

[60] S. Gatfaoui, A. Sagaama, N. Issaoui, T. Roisnel, H. Marouani, Synthesis, experimental, theoretical study and molecular docking of 1-ethylpiperazine-1,4-diium bis(nitrate), Solid State Sci. 106 (2020) 106236.

[61] F. Weinhold, C.R. Landis, Valency and Bonding: A Natural Bond Orbital DonorAcceptor Perspective, Cambridge University Press, Cambridge, 2005.

Fig. 1. ORTEP of $\mathrm{C}_{6} \mathrm{H}_{14} \mathrm{~N}\left(\mathrm{ClO}_{4}\right)$ with atoms-labeling scheme. Displacement ellipsoids are drawn at the $30 \%$ probability level. Hydrogen atoms are represented as small spheres (a) and Optimized molecular structure using DFT/B3LYP method and 6-311++G (d, p) basis set (b).

Fig. 2. Projection along the $\vec{b}$ axis of atomic arrangement of $\mathrm{C}_{6} \mathrm{H}_{14} \mathrm{~N}\left(\mathrm{ClO}_{4}\right)$ (a) Projection along the $\vec{a}$ axis of atomic arrangement of $\mathrm{C}_{6} \mathrm{H}_{14} \mathrm{~N}\left(\mathrm{ClO}_{4}\right)(\mathrm{b})$. The organic cations are represented by the atoms which have the greatest occupation for the clarity of the figure. 
Fig. 3. Hirshfeld surfaces mapped with $d_{\text {norm }}$ (a) (dotted lines "red" represent hydrogen bonds).

Fig. 4. Fingerprint plots of the different intercontacts and percentage of various intermolecular contacts contributed to the Hirshfeld surface in the $\left(\mathrm{C}_{6} \mathrm{H}_{14} \mathrm{~N}\right) \mathrm{ClO}_{4}$ compound.

Fig. 5. Graphical representation of the AIM analysis of $\left(\mathrm{C}_{6} \mathrm{H}_{14} \mathrm{~N}\right) \mathrm{ClO}_{4}$ : Red and Yellow dots indicate the position of the bond and ring critical points, respectively.

Fig. 6. Representation of different types of interactions in the monomer (a). Graph of the reduced density gradient vs. $\operatorname{sign}\left(\lambda_{2}\right) \rho$ for $\left(\mathrm{C}_{6} \mathrm{H}_{14} \mathrm{~N}\right) \mathrm{ClO}_{4}$.(b). Color code for different regions of interactions (c).

Fig. 7. The frontier molecular orbitals of $\left(\mathrm{C}_{6} \mathrm{H}_{14} \mathrm{~N}\right) \mathrm{ClO}_{4}$ with TD-DFT(B3LYP)6$311++\mathrm{G}(\mathrm{d}, \mathrm{p})$ method.

Fig. 8. Experimental (a) and theoretical (b) UV-visible spectrum of $\left(\mathrm{C}_{6} \mathrm{H}_{14} \mathrm{~N}\right) \mathrm{ClO}_{4}$. Optical band gap spectrum of $\mathrm{C}_{6} \mathrm{H}_{14} \mathrm{~N}\left(\mathrm{ClO}_{4}\right)$ obtained via Tauc model (c).

Fig. 9. The experimental and theoretical infrared spectra for $\left(\mathrm{C}_{6} \mathrm{H}_{14} \mathrm{~N}\right) \mathrm{ClO}_{4}$.

Fig. 10. Experimental ${ }^{13} \mathrm{C}$ NMR spectrum of $\left(\mathrm{C}_{6} \mathrm{H}_{14} \mathrm{~N}\right) \mathrm{ClO}_{4}$.

Table 1. Crystal data and experimental parameters used for the intensity data collection strategy and final results of the structure determination.

\begin{tabular}{|ll|}
\hline Temperature & $150 \mathrm{~K}$ \\
\hline Empirical formula & $\mathrm{C}_{6} \mathrm{H}_{14} \mathrm{~N}\left(\mathrm{ClO}_{4}\right)$ \\
\hline Formula weight $\left(\mathrm{g} \mathrm{mol}^{-1}\right)$ & 199.63 \\
\hline Crystal system & monoclinic \\
\hline Space group & $\mathrm{P} 2_{1} / \mathrm{c}$ \\
\hline a & $11.1501(19) \AA$ \\
\hline b & $8.4987(15) \AA$ \\
\hline c & $9.9517(16) \AA$ \\
\hline$\beta$ & $104.166{ }^{\circ}$ \\
\hline $\mathrm{Z}$ & 4 \\
\hline $\mathrm{V}$ & $914.4(3) \AA^{3}$ \\
\hline $\mathrm{F}(000)$ & 424 \\
\hline$\mu(\mathrm{Mo} \mathrm{K} \alpha)$ & $0.40 \mathrm{~mm}^{-1}$ \\
\hline
\end{tabular}




\begin{tabular}{|ll|}
\hline Index ranges & $-14 \leq \mathrm{h} \leq 14,-9 \leq \mathrm{k} \leq 11,-12 \leq 1 \leq 12$ \\
\hline Reflections collected & 8245 \\
\hline Independent reflections & 2083 \\
\hline Reflections with $\mathrm{I}>2 \sigma(\mathrm{I})$ & 1511 \\
\hline $\mathrm{R}_{\text {int }}$ & 0.043 \\
\hline Absorption correction: multi-scan & $\mathrm{T}_{\min }=0.830, \mathrm{~T}_{\max }=0.914$ \\
\hline Refined parameters & 103 \\
\hline $\mathrm{R}\left[\mathrm{F}^{2}>2 \sigma\left(\mathrm{F}^{2}\right)\right]$ & 0.053 \\
\hline $\mathrm{wR}\left(\mathrm{F}^{2}\right)$ & 0.143 \\
\hline Goodness of fit & 1.05 \\
\hline$\Delta \rho_{\max }=0.49$ e $\AA^{-3}$ & $\Delta \rho_{\min }=-0.56$ e $\AA^{-3}$ \\
\hline
\end{tabular}

Table 2. Optimized and experimental bond lengths and bond angles $\left(\AA,^{\circ}\right)$ parameters of $\mathrm{C}_{6} \mathrm{H}_{14} \mathrm{~N}\left(\mathrm{ClO}_{4}\right)$.

\begin{tabular}{|c|c|c|c|c|}
\hline & & $\begin{array}{c}\text { Theoretically } \\
\text { calculated }\end{array}$ & & Experimental \\
\hline & Gas & $\begin{array}{c}\text { In solution } \\
\text { (without } \\
\text { dispersion) }\end{array}$ & $\begin{array}{l}\text { In solution } \\
\text { (with } \\
\text { dispersion) }\end{array}$ & \\
\hline & & $\begin{array}{l}\text { Bond lengths } \\
\text { (§) }\end{array}$ & & \\
\hline $\mathrm{Cl}_{22}-\mathrm{O}_{23}$ & 1.4881 & 1.494 & 1.495 & $1.433(2)$ \\
\hline $\mathrm{Cl}_{22}-\mathrm{O}_{24}$ & 1.5282 & 1.506 & 1.509 & $1.4485(19)$ \\
\hline $\mathrm{Cl}_{22}-\mathrm{O}_{25}$ & 1.5255 & 1.494 & 1.495 & $1.433(2)$ \\
\hline $\mathrm{Cl}_{22}-\mathrm{O}_{26}$ & 1.4664 & 1.494 & 1.493 & $1.414(2)$ \\
\hline $\mathrm{N}_{1}-\mathrm{C}_{5}$ & 1.5093 & 1.511 & 1.51 & $1.493(9)$ \\
\hline $\mathrm{C}_{5}-\mathrm{C}_{7}$ & 1.5273 & 1.528 & 1.527 & $1.427(6)$ \\
\hline $\mathrm{C}_{7}-\mathrm{C}_{10}$ & 1.5365 & 1.536 & 1.535 & $1.500(6)$ \\
\hline $\mathrm{C}_{10}-\mathrm{C}_{13}$ & 1.5353 & 1.534 & 1.534 & $1.545(7)$ \\
\hline $\mathrm{C}_{13}-\mathrm{C}_{16}$ & 1.5354 & 1.534 & 1.534 & $1.535(7)$ \\
\hline $\mathrm{C}_{16}-\mathrm{C}_{19}$ & 1.5365 & 1.536 & 1.535 & $1.485(7)$ \\
\hline
\end{tabular}




\begin{tabular}{|c|c|c|c|c|}
\hline $\mathrm{C}_{19}-\mathrm{C}_{5}$ & 1.5272 & 1.527 & 1.526 & $1.474(7)$ \\
\hline $\mathbf{N}_{1}-\mathrm{H}_{2}$ & 1.019 & 1.024 & 1.024 & 0.91 \\
\hline $\mathrm{C}_{5}-\mathrm{H}_{6}$ & 1.0929 & 1.092 & 1.024 & 0.99 \\
\hline $\mathrm{C}_{7}-\mathrm{H}_{8}$ & 1.0993 & 1.097 & 1.097 & 0.99 \\
\hline & & $\begin{array}{c}\text { Bond angles } \\
\left({ }^{\circ}\right)\end{array}$ & & \\
\hline $\mathrm{O}_{23}-\mathrm{Cl}_{22}-\mathrm{O}_{24}$ & 108.524 & 108.9755 & 109.1184 & $108.70(12)$ \\
\hline $\mathrm{O}_{23}-\mathrm{Cl}_{22}-\mathrm{O}_{25}$ & 108.6111 & 109.8100 & 109.8428 & $109.08(15)$ \\
\hline $\mathrm{O}_{23}-\mathrm{Cl}_{22}-\mathrm{O}_{26}$ & 112.4173 & 109.7181 & 109.9126 & $110.87(16)$ \\
\hline $\mathrm{O}_{24}-\mathrm{Cl}_{22}-\mathrm{O}_{25}$ & 106.3431 & 109.2208 & 108.9705 & $108.91(13)$ \\
\hline $\mathrm{O}_{25}-\mathrm{Cl}_{22}-\mathrm{O}_{26}$ & 110.2759 & 109.2696 & 108.9190 & $110.40(14)$ \\
\hline $\mathrm{O}_{25}-\mathrm{Cl}_{22}-\mathrm{O}_{26}$ & 110.4592 & 109.8274 & 110.0520 & $108.85(15)$ \\
\hline $\mathrm{N}_{1}-\mathrm{C}_{5}-\mathrm{C}_{7}$ & 109.9902 & 109.4259 & 109.3941 & $114.1(7)$ \\
\hline $\mathrm{N}_{1}-\mathrm{C}_{5}-\mathrm{C}_{19}$ & 110.0908 & 109 & 109.6913 & $112.4(7)$ \\
\hline $\mathrm{C}_{7}-\mathrm{C}_{5}-\mathrm{C}_{19}$ & 112.5681 & 112.4545 & 112.2501 & $120.5(5)$ \\
\hline $\mathrm{C}_{5}-\mathrm{C}_{7}-\mathrm{C}_{10}$ & 109.9607 & 110.4073 & 110.1612 & $115.9(7)$ \\
\hline $\mathrm{C}_{7}-\mathrm{C}_{10}-\mathrm{C}_{13}$ & 111.41 & 111.5654 & 111.3913 & $116.7(7)$ \\
\hline $\mathrm{C}_{10}-\mathrm{C}_{13}-\mathrm{C}_{16}$ & 111.3136 & 111.3718 & 111.1711 & $109.9(7)$ \\
\hline $\mathrm{C}_{13}-\mathrm{C}_{16}-\mathrm{C}_{19}$ & 111.4202 & 111.5013 & 111.4362 & $113.7(5)$ \\
\hline $\mathrm{C}_{5}-\mathrm{C}_{19}-\mathrm{C}_{16}$ & 109.9663 & 110.4580 & 110.2288 & $114.8(5)$ \\
\hline $\mathrm{H}_{2}-\mathrm{N}_{1}-\mathrm{H}_{3}$ & 111.8565 & \begin{tabular}{|l|}
107.8070 \\
\end{tabular} & 107.9521 & 109.5 \\
\hline $\mathrm{H}_{2}-\mathrm{N}_{1}-\mathrm{C}_{5}$ & 112.6605 & 110.5131 & 110.5511 & 109.5 \\
\hline $\mathrm{N}_{1}-\mathrm{C}_{5}-\mathrm{H}_{6}$ & 104.473 & 105.2314 & 105.3428 & 102.2 \\
\hline $\mathrm{H}_{8}-\mathrm{C}_{7}-\mathrm{C}_{9}$ & 107.6133 & 109.9704 & 110.1228 & 108.3 \\
\hline
\end{tabular}


Table 3. Hydrogen-bond geometry $\left(\AA{ }^{\circ}{ }^{\circ}\right)$

\begin{tabular}{|c|c|c|c|c|}
\hline D-H...A & $\mathbf{D}-\mathbf{H}(\AA)$ & H...A $(\AA)$ & $\mathbf{D} \cdots \mathbf{A}(\AA)$ & D-H...A $\left(^{\circ}\right)$ \\
\hline N1-H1A...O1 ${ }^{\mathrm{i}}$ & 0.91 & 2.31 & $3.065(17)$ & 141 \\
\hline N1-H1A...O3 ${ }^{i i}$ & 0.91 & 2.62 & $3.165(17)$ & 119 \\
\hline $\mathrm{N} 1-\mathrm{H} 1 \mathrm{~B} \ldots \mathrm{O} 2^{\mathrm{i}}$ & 0.91 & 2.34 & $2.983(14)$ & 128 \\
\hline N1-H1B...O4 $4^{\text {iii }}$ & 0.91 & 2.41 & $3.123(17)$ & 136 \\
\hline $\mathrm{N} 1-\mathrm{H} 1 \mathrm{~B} \ldots . \mathrm{O} 3^{\mathrm{ii}}$ & 0.91 & 2.50 & $3.229(14)$ & 137 \\
\hline N1-H1C...O2 & 0.91 & 2.02 & $2.922(14)$ & 169 \\
\hline N1-H1C...O3 & 0.91 & 2.62 & $3.302(17)$ & 132 \\
\hline N1B-H1B1...O2 & 0.91 & 2.21 & $2.93(2)$ & 136 \\
\hline $\mathrm{N} 1 \mathrm{~B}-\mathrm{H} 1 \mathrm{~B} 1 \ldots \mathrm{O3}^{\mathrm{ii}}$ & 0.91 & 2.47 & $3.15(3)$ & 132 \\
\hline $\mathrm{N} 1 \mathrm{~B}-\mathrm{H} 1 \mathrm{~B} 2 \ldots \mathrm{O} 2^{\mathrm{i}}$ & 0.91 & 2.11 & $2.99 \overline{(2)}$ & 161 \\
\hline $\mathrm{N} 1 \mathrm{~B}-\mathrm{H} 1 \mathrm{~B} 2 \ldots \mathrm{O} 1^{\mathrm{i}}$ & 0.91 & 2.34 & $3.05(3)$ & 135 \\
\hline $\mathrm{N} 1 \mathrm{~B}-\mathrm{H} 1 \mathrm{B3} . . .04^{\mathrm{iii}}$ & 0.91 & 2.48 & $3.14(3)$ & 130 \\
\hline $\mathrm{N} 1 \mathrm{~B}-\mathrm{H} 1 \mathrm{B3} . . . \mathrm{O3}^{\mathrm{iii}}$ & 0.91 & 2.63 & $3.25(2)$ & 126 \\
\hline N1B-H1B3...O3 & 0.91 & 2.64 & $3.32(3)$ & 131 \\
\hline $\mathrm{C} 2-\mathrm{H} 2 \mathrm{~A} \ldots . .3^{\mathrm{ii}}$ & 0.99 & 2.45 & $3.325(6)$ & 146 \\
\hline $\mathrm{C} 2-\mathrm{H} 2 \mathrm{~B} \ldots \mathrm{O} 1^{\mathrm{iv}}$ & 0.99 & 2.36 & $3.183(6)$ & 140 \\
\hline C6-H6А...O4 $4^{\text {iii }}$ & 0.99 & 2.49 & $3.263(8)$ & 135 \\
\hline
\end{tabular}

Symmetry codes: (i) $-\mathrm{x}+1, \mathrm{y}+1 / 2,-\mathrm{z}+1 / 2$; (ii) $\mathrm{x},-\mathrm{y}+1 / 2, \mathrm{z}-1 / 2$; (iii) $-\mathrm{x}+1,-\mathrm{y}+1,-\mathrm{z}+1$; (iv) $-\mathrm{x}+1,-\mathrm{y},-\mathrm{z}+1$. 
Table 4. Enrichment ratio of different inter-contact and percentage of each atom on the surface Hirshfeld in $\left(\mathrm{C}_{6} \mathrm{H}_{14} \mathrm{~N}\right) \mathrm{ClO}_{4}$.

\begin{tabular}{|l|l|l|}
\hline Enrichment & H & O \\
\hline H & 0.88 & 1.29 \\
\hline \% Surface & & 0.28 \\
\hline
\end{tabular}

Table 5. Topological parameters (distance, electron density, Laplacien, Potential energy density, interaction energy, ellipticity and eta index) of the $\left(\mathrm{C}_{6} \mathrm{H}_{14} \mathrm{~N}\right) \mathrm{ClO}_{4}$ compound.

\begin{tabular}{|c|c|c|c|c|c|c|}
\hline & $\mathrm{H}_{9} \ldots \mathrm{O}_{23}$ & $\mathrm{H}_{4} \ldots \mathrm{O}_{24}$ & $\mathrm{H}_{6} \ldots \mathrm{O}_{25}$ & $\mathbf{R C P}$ & NRCP1 & NRCP2 \\
\hline Distance (Á) & 2.7285 & 1.8799 & 3.2006 & - & - & - \\
\hline $\begin{array}{l}\text { Density of electrons } \\
\rho(r) \text { (a.u.) }\end{array}$ & 0.00602 & 0.02967 & 0.00264 & 0.01843 & 0.00359 & 0.00256 \\
\hline $\begin{array}{ll}\text { Laplacian } & \text { of } \\
\text { electron density } & \nabla^{2} \\
\rho(r) \text { (a.u.) } & \end{array}$ & 0.0 & 0.09187 & 0.00984 & 0.11298 & 0.01321 & 0.01007 \\
\hline $\begin{array}{l}\text { Potential energy } \\
\text { density V(r) (a.u.) }\end{array}$ & -0.00334 & -0.02198 & -0.00139 & -0.01679 & -0.00204 & -0.00136 \\
\hline $\begin{array}{l}\text { Interaction energy } \\
\left(\mathrm{E}_{\text {int }}\right)\left(\mathrm{kJ} . \mathrm{mol}^{-1}\right)\end{array}$ & -4.34 & -28.57 & -1.81 & - & - & - \\
\hline Ellipticity $(\varepsilon)$ & 0.1470 & 0.0566 & 0.7266 & -1.2465 & -2.1442 & -2.0482 \\
\hline Eta index $(\zeta)$ & 0.1873 & 0.2466 & 0.1381 & 0.2420 & 0.1572 & 0.1317 \\
\hline
\end{tabular}

BCP: bond critical point, RCP: ring critical point, NRCP: new ring critical point. 
Table 6. Thermodynamic properties of $\mathrm{C}_{6} \mathrm{H}_{14} \mathrm{~N}\left(\mathrm{ClO}_{4}\right)$ at B3LYP/6-311++ (d,p) level in gas phase (with dispersion effect) and in solution (with/without dispersion effect) at temperature $\mathrm{T}=298.15 \mathrm{~K}$ and pressure $\mathrm{P}=1 \mathrm{~atm}$.

\begin{tabular}{|l|l|l|l|}
\hline & \multicolumn{1}{|c|}{ In Gas phase } & \multicolumn{2}{c|}{ In solution } \\
\cline { 3 - 4 } & With dispersion & With dispersion & Without dispersion \\
\hline E(RB3LYP) ( Hartree) & -1052.7978 & -1052.8454 & -1052.8217 \\
\hline Dipole Moment(Debye) & 10.88504 & 18.20596 & 19.562398 \\
\hline Polarizability(a.u) & 112.22611 & 155.83876 & 155.5042 \\
\hline HyperPolarizability(a.u) & 391.90919 & 196.82125 & 146.93182 \\
\hline $\begin{array}{l}\text { Zero-point Energy } \\
\text { Correction(Hartree) }\end{array}$ & 0.217645 & 0.216731 & 0.21597 \\
\hline $\begin{array}{l}\text { E(Thermal)( kcal/mol) } \\
\text { Heat Capacity (Cv) }\end{array}$ & 144.531 & & 143.924 \\
\hline (cal/mol.K) & 47.318 & 48.015 & 48.376 \\
\hline Entropy (S) (cal/mol.K) & 115.618 & & 123.531 \\
\hline
\end{tabular}


Table 7. Global reactivity descriptors and calculated frontier molecular orbital parameters in gas and in solution phase for $\left(\mathrm{C}_{6} \mathrm{H}_{14} \mathrm{~N}\right) \mathrm{ClO}_{4}$.

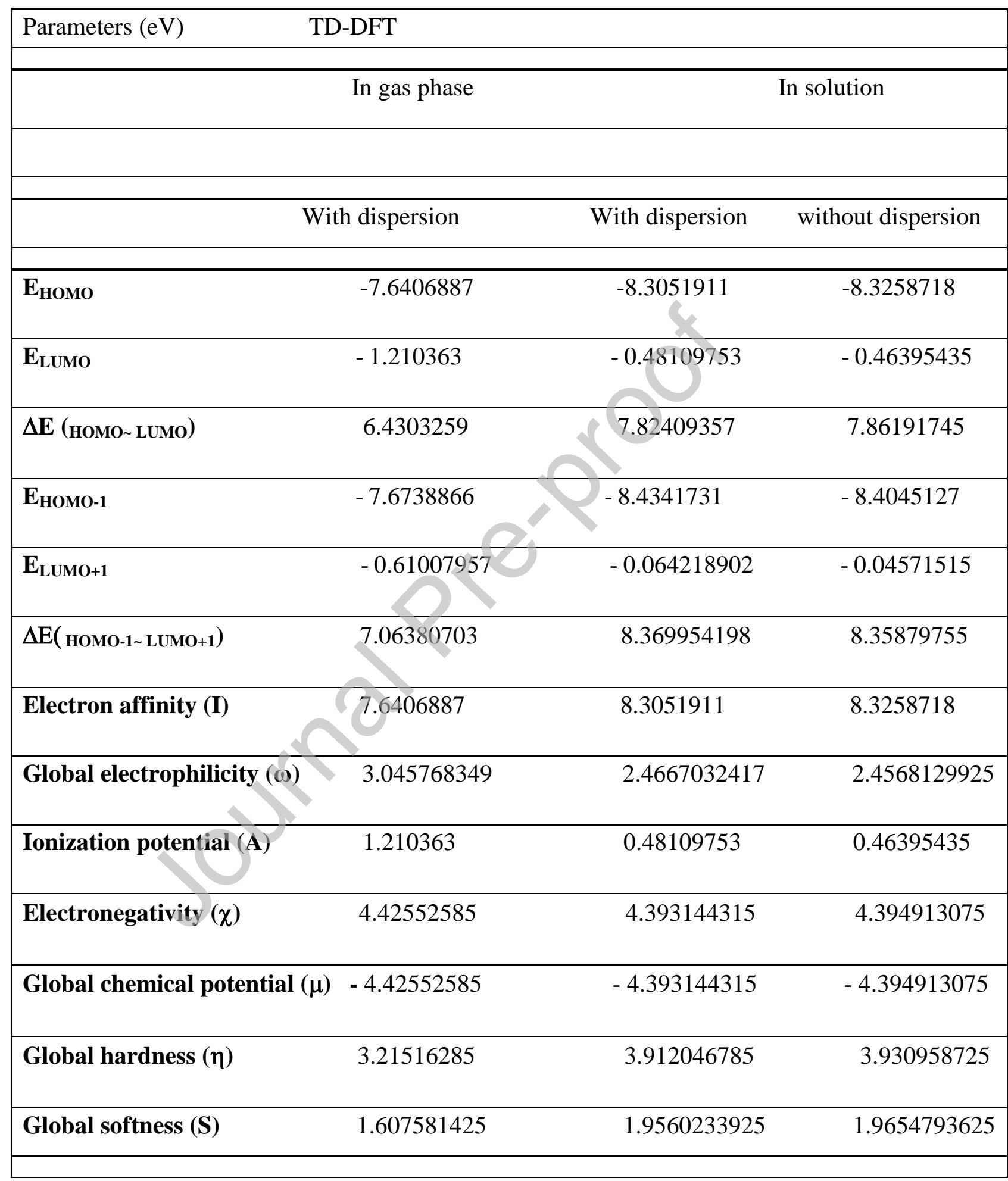


Table 8. Experimental and theoretical IR frequencies $\left(\mathrm{cm}^{-1}\right)$ and their assignments for $\left(\mathrm{C}_{6} \mathrm{H}_{14} \mathrm{~N}\right) \mathrm{ClO}_{4}$ in gas phase by using the B3LYP/6-311++G(d,p) Method

\begin{tabular}{|c|c|c|c|c|}
\hline Experimental & Theoretical & & & $\begin{array}{l}\text { Vibrational assignments } \\
\text { (\% PED) }\end{array}$ \\
\hline IR & Unscaled & Scaled & IR & \\
\hline 3457 & 3492 & 3345 & 134.37 & vNH (99) \\
\hline 3427 & 3443 & 3298 & 167.74 & $v \mathrm{NH}(95)$ \\
\hline 3132 & 3280 & 3142 & 742.17 & vNH (96) \\
\hline 2952 & 3090 & 2960 & 71.86 & $\mathrm{vCH}(91)$ \\
\hline 2952 & 3076 & 2947 & 21.5 & $\checkmark \mathrm{CH}(84)$ \\
\hline 2952 & 3068 & 2939 & 97.19 & $\mathrm{vCH}(85)$ \\
\hline 2952 & 3065 & $293^{\prime}$ & 64.63 & $\mathrm{vCH}(88)$ \\
\hline 2952 & 3061 & 2932 & 73.91 & vCH (87) \\
\hline 2952 & 3058 & 2930 & 90.43 & $\mathrm{vCH}(86)$ \\
\hline 2859 & 3018 & 2891 & 96.13 & $\mathrm{vCH}(87)$ \\
\hline 2859 & 3015 & 2888 & 47.27 & $\mathrm{vCH}(90)$ \\
\hline 2859 & 3015 & 2888 & 17.34 & $\mathrm{vCH}(85)$ \\
\hline 2859 & 3011 & 2884 & 32.363 & $v \mathrm{CH}(86)$ \\
\hline 2859 & 3008 & 2882 & 28.77 & $v \mathrm{CH}(87)$ \\
\hline 1590 & 1620 & 1592 & 63.91 & $\beta \mathrm{HNH}(78)$ \\
\hline 1581 & 1607 & 1580 & 45.33 & $\beta \mathrm{HNH}(85)$ \\
\hline 1502 & 1498 & 1473 & 98.74 & $\delta \mathrm{HNHO}(45) \quad \beta \mathrm{HCH}(35)$ \\
\hline
\end{tabular}




\begin{tabular}{|c|c|c|c|c|}
\hline 1447 & 1487 & 1462 & 78.01 & $\delta \mathrm{HNHO}(37) \beta \mathrm{HCH}(52)$ \\
\hline 1447 & 1479 & 1454 & 8.54 & $\beta \mathrm{HCH}(81)$ \\
\hline 1447 & 1478 & 1453 & 9.5 & $\beta \mathrm{HCH}(83)$ \\
\hline 1447 & 1473 & 1448 & 0.5 & $\beta \mathrm{HCH}(87)$ \\
\hline \multirow[t]{16}{*}{1447} & 1471 & 1446 & 9.46 & $\beta \mathrm{HCH}(88)$ \\
\hline & 1426 & 1402 & 42.38 & $\delta \mathrm{HCCC}(52)$ \\
\hline & 1396 & 1372 & 4.55 & $\beta \mathrm{HCC}(64)$ \\
\hline & 1380 & 1357 & 1.17 & $\delta \mathrm{HCCC}(5$ \\
\hline & 1376 & 1352 & 1.71 & $\beta \mathrm{HCC}(63)$ \\
\hline & 1374 & 1351 & 3.59 & $\beta \mathrm{HCC}(55)$ \\
\hline & 1366 & 1343 & 0.63 & $\beta \mathrm{HCC}(72)$ \\
\hline & 1347 & 132 & 0.58 & $\beta \mathrm{HCC}(73)$ \\
\hline & 1308 & 1286 & 3.64 & $\beta \mathrm{HCC}(74)$ \\
\hline & 1286 & 1264 & 3.48 & $\beta \mathrm{HCC}(71)$ \\
\hline & 128 & 1258 & 2.6 & $\beta \mathrm{HCC}(47) \delta \mathrm{HCCC}(12)$ \\
\hline & 1244 & 1223 & 13.93 & $\beta \mathrm{HCC}(23) \vee C C(12) \beta H C C(12)$ \\
\hline & 1190 & 1169 & 6.94 & $\delta \mathrm{CCCC} \mathrm{(44)} \delta \mathrm{HCCC} \mathrm{(15)}$ \\
\hline & 1140 & 1120 & 15.53 & $\beta \mathrm{HCC}(44) \quad v C C(12)$ \\
\hline & 1101 & 1082 & 2.13 & $\beta \mathrm{HCC}(63) \quad v C C$ (17) \\
\hline & 1084 & 1066 & 3.72 & $\beta \mathrm{HCC}(17) v \mathrm{CC}(56)$ \\
\hline 1079 & 1071 & 1053 & 5.41 & $\beta C C C(29) \quad \delta \mathrm{HNHO}(13)$ \\
\hline 1079 & 1042 & 1024 & 11.57 & $\mathrm{vCC}(62)$ \\
\hline
\end{tabular}




\begin{tabular}{|c|c|c|c|c|}
\hline & 1022 & 1005 & 31.27 & $\begin{array}{l}\nu \mathrm{CC}(12) \quad \beta C C C \text { (13) } \\
\beta \mathrm{HNC}(11)\end{array}$ \\
\hline & 1005 & 988 & 27.88 & $v \mathrm{CC}(30) \delta \mathrm{HNHO}(32)$ \\
\hline 1079 & 955 & 939 & 16.64 & $v \mathrm{NC}(62)$ \\
\hline 1079 & 945 & 929 & 612.89 & $\mathrm{vClO}(88)$ \\
\hline 923 & 940 & 924 & 409.17 & $v \mathrm{ClO}(62) \quad \delta \mathrm{HCCC}(13)$ \\
\hline 923 & 939 & 924 & 245.09 & $\nu \mathrm{ClO}(33) \quad \delta \mathrm{HCCC}(24)$ \\
\hline 923 & 905 & 890 & 627.59 & $v \mathrm{ClO}(83)$ \\
\hline 923 & 899 & 884 & 18.39 & $\delta \operatorname{HCCC}(10)$ vCC (48) \\
\hline 923 & 884 & 869 & 9.94 & $\delta \mathrm{HCCN}(33)$ \\
\hline 923 & 853 & 838 & 4.74 & $v C C(76)$ \\
\hline 923 & 811 & 797 & 23.72 & $\mathrm{vClO}(94)$ \\
\hline & 805 & & 0.07 & $\begin{array}{l}\beta \mathrm{HCC}(16) v \mathrm{CC}(12) \\
\delta \mathrm{HCCC}(45)\end{array}$ \\
\hline & 7 & 775 & 0.66 & $\nu \mathrm{CC}(58) \beta \mathrm{CCC}(18)$ \\
\hline 624 & 556 & 547 & 44.98 & $\begin{array}{l}\delta \mathrm{HCCN}(15) \\
\gamma \mathrm{OOOCl}(29) \beta \mathrm{CCC}(11) \delta \mathrm{HCCN} \\
(11)\end{array}$ \\
\hline 624 & 550 & 541 & 35.1 & rOOOCl (41) \\
\hline 624 & 548 & 538 & 49.94 & $\beta \mathrm{OClO}(79)$ \\
\hline 624 & 542 & 533 & 69.72 & $\beta \mathrm{OClO}(84)$ \\
\hline 453 & 464 & 456 & 14.69 & $\gamma \mathrm{NCCC}(43)$ \\
\hline 453 & 457 & 450 & 5.77 & $\beta C C C$ (54) \\
\hline
\end{tabular}




\begin{tabular}{|c|c|c|c|c|}
\hline 453 & 413 & 406 & 4.09 & $\beta C C C$ (55) \\
\hline 453 & 401 & 394 & 1.47 & $\beta \mathrm{OClO}(78)$ \\
\hline 453 & 394 & 387 & 0.02 & $\beta \mathrm{OClO}(88)$ \\
\hline- & 360 & 354 & 11.82 & $\overline{\delta H N O C l}(52) \quad \beta C C N(21)$ \\
\hline- & 343 & 337 & 5.79 & $\delta C C C C(20) \quad \delta H C C C ~(32)$ \\
\hline - & 327 & 321 & 23.73 & $\delta \mathrm{HNOCl}(30) \quad \beta C C N(39)$ \\
\hline- & 240 & 236 & 0.26 & $\delta \mathrm{HCCC}(19) \quad \delta C C C C(66)$ \\
\hline - & 178 & 175 & 28.89 & $\delta \mathrm{CCCC}(41) \vee v \mathrm{ON}(14)$ \\
\hline- & 132 & 130 & 33.07 & $\mathrm{vON}(66)$ \\
\hline - & 80 & 79 & 9.42 & $\beta \mathrm{HOCl}(76)$ \\
\hline - & 62 & 61 & 11.32 & $\beta \mathrm{HNC}(37) \quad \delta \mathrm{NHOCl}(42)$ \\
\hline- & 48 & 4 & 8.39 & $\beta C N O(64) \quad \delta N O C l O(11)$ \\
\hline- & 39 & & 0.85 & $\delta \mathrm{NOClO}(84)$ \\
\hline- & 22 & 2 & 0.99 & 8NHOCl (87) \\
\hline
\end{tabular}

Table 9. Theoretical and Experimental ${ }^{13} \mathrm{C}$ chemical shift values of $\left(\mathrm{C}_{6} \mathrm{H}_{14} \mathrm{~N}\right) \mathrm{ClO}_{4}$.

\begin{tabular}{|l|l|l|}
\hline Atoms & $\begin{array}{l}\text { Experimental } \\
\text { chemical } \\
\text { shift in ppm }\end{array}$ & $\begin{array}{l}\text { Calculated } \\
\text { chemical } \\
\text { shift in } \\
\text { ppm }\end{array}$ \\
\hline & & $\begin{array}{l}\text { TMS } \\
\text { B3LYP/6- } \\
311+\text { G } \\
(2 \mathrm{~d}, \mathrm{p}) \mathrm{GIAO}\end{array}$ \\
\hline C1 & 49.79 & 62.9622 \\
\hline C2 & 30.83 & 35.8008 \\
\hline C3 & 24.15 & 29.9266 \\
\hline
\end{tabular}




\begin{tabular}{|l|l|l|}
\hline C4 & 24.99 & 29.2161 \\
\hline C5 & 24.15 & 29.9303 \\
\hline C6 & 30.83 & 35.7989 \\
\hline
\end{tabular}

Table 10. Second order perturbation theory analysis of the Fock matrix in NBO basis of optimized structure of $\mathrm{C}_{6} \mathrm{H}_{14} \mathrm{~N}\left(\mathrm{ClO}_{4}\right)$.

\begin{tabular}{|c|c|c|c|c|}
\hline Donor NBO(i) & Acceptor NBO(j) & $\begin{array}{c}{ }^{\mathrm{a}} \mathrm{E}(2) \\
\mathrm{kcal} \mathrm{mol}^{-1}\end{array}$ & $\begin{array}{c}{ }^{b} E(j)-E(i) \\
\text { a.u. }\end{array}$ & $\begin{array}{c}{ }^{c} \mathrm{~F}(\mathrm{i}, \mathrm{j}) \\
\text { a.u. }\end{array}$ \\
\hline$\sigma(\mathrm{C} 5-\mathrm{H} 6)$ & $\sigma^{*}(\mathrm{~N} 1-\mathrm{H} 2)$ & 2.65 & 1.03 & 0.047 \\
\hline$\sigma(\mathrm{C} 5-\mathrm{H} 6)$ & $\sigma^{*}(\mathrm{C} 7-\mathrm{H} 8)$ & 3.42 & 1.08 & 0.055 \\
\hline$\sigma(\mathrm{C} 5-\mathrm{H} 6)$ & $\sigma^{*}(\mathrm{C} 19-\mathrm{H} 21)$ & 3.27 & 1.07 & 0.053 \\
\hline$\sigma(\mathrm{C} 5-\mathrm{C} 7)$ & $\sigma^{*}(\mathrm{C} 5-\mathrm{H} 6)$ & 2.29 & 1.2 & 0.047 \\
\hline$\sigma(\mathrm{C} 5-\mathrm{C} 7)$ & $\sigma^{*}(\mathrm{C} 5-\mathrm{C} 19)$ & 2.34 & 1.11 & 0.046 \\
\hline$\sigma(\mathrm{C} 5-\mathrm{C} 19)$ & $\sigma^{*}(\mathrm{C} 5-\mathrm{C} 7)$ & 2.33 & 1.15 & 0.046 \\
\hline$\sigma(\mathrm{C} 7-\mathrm{H} 9)$ & $\sigma^{*}(\mathrm{C} 5-\mathrm{C} 19)$ & 4.72 & 0.95 & 0.06 \\
\hline$\sigma(\mathrm{C} 7-\mathrm{H} 9)$ & $\sigma^{*}(\mathrm{C} 10-\mathrm{C} 13)$ & 3.11 & 0.91 & 0.048 \\
\hline$\sigma(\mathrm{C} 7-\mathrm{C} 10)$ & $\sigma^{*}(\mathrm{~N} 1-\mathrm{C} 5)$ & 4.93 & 0.84 & 0.058 \\
\hline$\sigma(\mathrm{C} 7-\mathrm{C} 10)$ & $\sigma^{*}(\mathrm{C} 5-\mathrm{C} 7)$ & 2.08 & 1.09 & 0.043 \\
\hline$\sigma(\mathrm{C} 10-\mathrm{H} 11)$ & $\sigma^{*}(\mathrm{C} 5-\mathrm{C} 7)$ & 2.71 & 1.01 & 0.047 \\
\hline$\sigma(\mathrm{C} 10-\mathrm{H} 11)$ & $\sigma^{*}(\mathrm{C} 13-\mathrm{C} 16)$ & 2.23 & 0.91 & 0.04 \\
\hline$\sigma(\mathrm{C} 13-\mathrm{H} 14)$ & $\sigma^{*}(\mathrm{C} 7-\mathrm{C} 10)$ & 2.58 & 0.96 & 0.044 \\
\hline$\sigma(\mathrm{C} 13-\mathrm{H} 14)$ & $\sigma^{*}(\mathrm{C} 16-\mathrm{C} 19)$ & 2.6 & 0.96 & 0.045 \\
\hline$\sigma(\mathrm{C} 16-\mathrm{H} 17)$ & $\sigma^{*}(\mathrm{C} 19-\mathrm{H} 21)$ & 2.37 & 1.06 & 0.045 \\
\hline$\sigma(\mathrm{C} 16-\mathrm{H} 18)$ & o*(C5-C19) & 3.19 & 0.96 & 0.049 \\
\hline$\sigma(\mathrm{C} 16-\mathrm{H} 18)$ & $\sigma^{*}(\mathrm{C} 10-\mathrm{C} 13)$ & 2.22 & 0.92 & 0.04 \\
\hline$\sigma(\mathrm{C} 16-\mathrm{C} 19)$ & $\sigma^{*}(\mathrm{~N} 1-\mathrm{C} 5)$ & 3.86 & 0.86 & 0.052 \\
\hline$\sigma(\mathrm{C} 19-\mathrm{H} 20)$ & $\sigma^{*}(\mathrm{C} 5-\mathrm{C} 7)$ & 3.59 & 1.04 & 0.055 \\
\hline$\sigma(\mathrm{C} 19-\mathrm{H} 20)$ & $\sigma^{*}(\mathrm{C} 13-\mathrm{C} 16)$ & 3.03 & 0.94 & 0.048 \\
\hline$\sigma(\mathrm{C} 19-\mathrm{H} 21)$ & $\sigma^{*}(\mathrm{C} 16-\mathrm{H} 17)$ & 2 & 1.11 & 0.042 \\
\hline $\mathrm{LP}(\mathrm{O} 24)$ & $\sigma^{*}(\mathrm{~N} 1-\mathrm{H} 4)$ & 2.07 & 1.36 & 0.047 \\
\hline $\mathrm{LP}(\mathrm{O} 24)$ & $\sigma^{*}(\mathrm{~N} 1-\mathrm{H} 4)$ & 6.96 & 0.82 & 0.07 \\
\hline $\mathrm{LP}(\mathrm{O} 23)$ & $\sigma^{*}(\mathrm{Cl} 22-\mathrm{O} 24)$ & 9.57 & 0.49 & 0.063 \\
\hline $\mathrm{LP}(\mathrm{O} 23)$ & $\sigma^{*}(\mathrm{Cl} 22-\mathrm{O} 26)$ & 18.3 & 0.55 & 0.09 \\
\hline $\mathrm{LP}(\mathrm{O} 23)$ & $\sigma *(\mathrm{Cl} 22-\mathrm{O} 24)$ & 10.61 & 0.49 & 0.066 \\
\hline $\mathrm{LP}(\mathrm{O} 23)$ & $\sigma^{*}(\mathrm{Cl} 22-\mathrm{O} 25)$ & 17.88 & 0.52 & 0.087 \\
\hline $\mathrm{LP}(\mathrm{O} 24)$ & $\sigma^{*}(\mathrm{Cl} 22-\mathrm{O} 23)$ & 11.75 & 0.55 & 0.074 \\
\hline $\mathrm{LP}(\mathrm{O} 24)$ & $\sigma^{*}(\mathrm{Cl} 22-\mathrm{O} 26)$ & 13.59 & 0.57 & 0.08 \\
\hline $\mathrm{LP}(\mathrm{O} 24)$ & $\sigma^{*}(\mathrm{Cl} 22-\mathrm{O} 23)$ & 5.4 & 0.56 & 0.05 \\
\hline $\mathrm{LP}(\mathrm{O} 24)$ & $\sigma *(\mathrm{Cl} 22-\mathrm{O} 25)$ & 16.42 & 0.55 & 0.087 \\
\hline $\mathrm{LP}(\mathrm{O} 24)$ & $\sigma^{*}(\mathrm{Cl} 22-\mathrm{O} 26)$ & 3.63 & 0.58 & 0.042 \\
\hline
\end{tabular}




\begin{tabular}{|l|l|c|c|c|}
\hline $\mathrm{LP}(\mathrm{O} 25)$ & $\sigma^{*}(\mathrm{Cl} 22-\mathrm{O} 23)$ & 6.74 & 0.54 & 0.055 \\
\hline $\mathrm{LP}(\mathrm{O} 25)$ & $\sigma^{*}(\mathrm{Cl} 22-\mathrm{O} 24)$ & 2.85 & 0.51 & 0.035 \\
\hline $\mathrm{LP}(\mathrm{O} 25)$ & $\sigma^{*}(\mathrm{Cl} 22-\mathrm{O} 26)$ & 17.98 & 0.57 & 0.092 \\
\hline $\mathrm{LP}(\mathrm{O} 25)$ & $\sigma^{*}(\mathrm{Cl} 22-\mathrm{O} 23)$ & 11.81 & 0.55 & 0.073 \\
\hline $\mathrm{LP}(\mathrm{O} 25)$ & $\sigma^{*}(\mathrm{Cl} 22-\mathrm{O} 24)$ & 16.07 & 0.51 & 0.083 \\
\hline $\mathrm{LP}(\mathrm{O} 26)$ & $\sigma^{*}(\mathrm{Cl} 22-\mathrm{O} 23)$ & 13.9 & 0.53 & 0.078 \\
\hline $\mathrm{LP}(\mathrm{O} 26)$ & $\sigma^{*}(\mathrm{Cl} 22-\mathrm{O} 25)$ & 17.34 & 0.53 & 0.087 \\
\hline $\mathrm{LP}(\mathrm{O} 26)$ & $\sigma^{*}(\mathrm{Cl} 22-\mathrm{O} 23)$ & 7.02 & 0.53 & 0.055 \\
\hline $\mathrm{LP}(\mathrm{O} 26)$ & $\sigma^{*}(\mathrm{Cl} 22-\mathrm{O} 24)$ & 21.95 & 0.5 & 0.095 \\
\hline $\mathrm{LP}(\mathrm{O} 26)$ & $\sigma^{*}(\mathrm{Cl} 22-\mathrm{O} 25)$ & 3.57 & 0.53 & 0.039 \\
\hline$\sigma^{*}(\mathrm{Cl} 22-\mathrm{O} 23)$ & $\sigma^{*}(\mathrm{Cl} 22-\mathrm{O} 26)$ & 8.13 & 0.02 & 0.025 \\
\hline$\sigma^{*}(\mathrm{Cl} 22-\mathrm{O} 24)$ & $\sigma^{*}(\mathrm{Cl} 22-\mathrm{O} 23)$ & 3.79 & 0.03 & 0.02 \\
\hline$\sigma^{*}(\mathrm{Cl} 22-\mathrm{O} 24)$ & $\sigma^{*}(\mathrm{Cl} 22-\mathrm{O} 25)$ & 6.5 & 0.03 & 0.024 \\
\hline$\sigma^{*}(\mathrm{Cl} 22-\mathrm{O} 24)$ & $\sigma^{*}(\mathrm{Cl} 22-\mathrm{O} 26)$ & 3.66 & 0.05 & 0.026 \\
\hline$\sigma^{*}(\mathrm{Cl} 22-\mathrm{O} 25)$ & $\sigma^{*}(\mathrm{Cl} 22-\mathrm{O} 26)$ & 3.65 & 0.03 & 0.019 \\
\hline
\end{tabular}

${ }^{\mathrm{a}} \mathrm{E}(2)$ means energy of hyper conjugate interactions $\geq 2$ (stabilization energy in $\mathrm{kcal}^{\mathrm{mol}}{ }^{-1}$ ). ${ }^{b}$ Energy difference between donor and acceptor $\mathrm{i}$ and $\mathrm{j}$ NBO orbitals in a.u.

${ }^{c} \mathrm{~F}(\mathrm{i}, \mathrm{j})$ is the Fock matrix element between $\mathrm{i}$ and $\mathrm{j}$ NBO orbitals in a.u. 